\title{
Absence of Endothelium in Invertebrate Blood Vessels: Significance of Endothelium and Sympathetic Nerve/Medial Smooth Muscle in the Vertebrate Vascular System
}

\author{
Tatsuro Shigei ${ }^{1}$, Hiromichi Tsuru ${ }^{2}$, Naohisa Ishikawa ${ }^{3}$ and Koichi Yoshioka ${ }^{4, *}$ \\ ${ }^{1}$ Department of Pharmacology, Nagoya University School of Medicine, Showa-ku, Nagoya 466-8550, Japan \\ ${ }^{2}$ Department of Pharmacology, Toho University School of Medicine, Ohta-ku, Tokyo 143-8540, Japan \\ ${ }^{3}$ Department of Pharmacology, Aichi Medical University, Nagakute-cho, Aichi-gun, Aichi 480-1195, Japan \\ ${ }^{4}$ Department of Biochemistry and Biophysics, Graduate School of Allied Health Sciences, Tokyo Medical and Dental University, \\ Bunkyo-ku, Tokyo 113-8519, Japan
}

Received July 16, 2001 Accepted September 26, 2001

\begin{abstract}
In the course of evolution, two remarkable changes seem to have occurred in vertebrate circulation: the appearance and development of the "endothelium or endothelial tubular system" and "sympathetic nerve/medial smooth muscle system". In the present article, some relevant literature is reviewed and discussed. Absence of endothelium in the vascular wall of most invertebrates had been known and was confirmed by recent electron microscopic studies. The medial smooth muscle is rather proper to vertebrate vessels. It seems to have appeared after emergence of and in association with the endothelial tubular system. Phylogenetically, the parasympathetic nervous system is thought to be older than the sympathetic system. The former is distributed to viscera and the latter developed in close relation with the vascular system. It is assumed that during evolution, a circulatory system composed of the heart and endothelial tubular system first formed in vertebrates, medial smooth muscle then appeared for regulation of the system, and innervation of the muscle tissue took place. This sequence of development assumed for phylogenesis is actually realized in the ontogenetic processes. We thus propose a hypothesis that the "sympathetic nerve/medial smooth muscle system" may be regarded as a new neuroeffector mechanism that developed for systemic regulation of the endothelium-lined closed vascular system in vertebrates. A few implications of the hypothesis are presented.
\end{abstract}

Keywords: Endothelium, Vascular muscle, Sympathetic nerve, Invertebrate vessel, Evolution of vascular wall

\section{Introduction}

It has been known that there is no endothelium in the vascular wall of most invertebrates, and that, in this respect, the vertebrate vascular system is distinct from that of invertebrates including prochordates. In view of the current interest in "endothelium", this fact deserves more attention.

Recently, in our discussions about our studies on the dog venous system $(1-5)$, we considered the possibility that, not only the endothelium, but also the medial smooth muscle and sympathetic nerves appeared anew in the vascular wall of vertebrates during the course of evolution. Based on such considerations, we propose a hypothesis

*Corresponding author. FAX: $+81-3-5803-5362$

E-mail: k.yoshioka.mtec@tmd.ac.jp that "the sympathetic nerve/medial smooth muscle system" may be regarded as a new neuroeffector mechanism that developed in vertebrates for systemic regulation of "the endothelium-lined closed vascular system" (6).

In the present article, the relevant literature is briefly reviewed and discussed from an embryological viewpoint. In addition, a few implications will be presented.

\section{Phylogenetic aspects of the three components of the vascular wall}

\section{1) Endothelium}

It seems that by the $1950 \mathrm{~s}$, a considerable amount of information had been obtained about the absence of endothelium in the invertebrate circulatory system, using the light microscope. Thereafter, electron microscopic studies 
have brought more precise findings and clarification.

Leydig (1857) (7) reported on the structure of the wall of annelid blood vessels. He described three layers in the contractile vessels. The innermost layer, tunica intima, was a homogeneous connective tissue membrane. He found no endothelium. Tunica muscularis consisted of muscle fibers derived from peritoneal cells, and tunica adventitia was the peritoneal covering. Since then, much discussion continued about the actual composition of the annelid vessel wall, and presence or absence of true endothelium. The problem was settled by recent ultrastructural studies, particularly by that of Nakao (ref. 8, quoted in the "Vascular muscle" section).

Altschul (1954) stated in his monograph "Endothelium" (9) that i) there is no endothelium in the heart or various parts of the vessels of annelids, molluscs, crustaceans, insects, worms and spiders, and even in amphioxus. ii) In annelids, mollusks and crustaceans, the intima is mainly a homogeneous lining (Leydig's membrane). The vessels of worms and spiders are merely homogeneous plasmatic tubes. iii) Vertebrate blood vessels are primarily endothelial tubes with secondary, accessorial walls. The developing endothelium may at least induce the surrounding mesenchyme to differentiate into the media and, perhaps, into the adventitia. This points to the paramount importance of the endothelium. (He further made reference to the possibility that a failure in development of parts of the endothelial tube which, in many cases, amounts to a failure of differentiation of mesenchymal cells, will result in anomalies and malformations of the cardiovascular system. In the present article, this problem is not discussed.)

Martin and Johansen (10) stressed the need for collecting and integrating information concerning the presence and absence of endothelium in invertebrate vasculature, because this information had been scattered throughout the literature.

Mori (11) and Mori and Shida (12) discussed from a phylogenetic viewpoint the development of the vascular system, the centralization of the pulsatile portion (heart), the structure of vascular wall, and the differences between invertebrate and vertebrate vessels. Endothelium is lacking in many invertebrate species, although it exceptionally exists in a few animal groups (nemertinea, octopus and squid). In vertebrates, blood vessels first develop as endothelial tubes, and then, layers of the wall are formed by accumulation of surrounding mesenchymal cells. They pointed out that such a process itself characterizes the vertebrate blood vessels.

Electron microscopic studies showed the absence of endothelium in tunicate (13), insect (14), annelid (8), shrimp (15), bivalve (16), echinodermata (17) and amphioxus $(18-21)$. Exceptionally, endothelial or endothelium-like cells are shown to exist in some vessels of invertebrates: nemertinea (11) or cephalopods $(22,23$; see "Vascular muscle" section). Relation between these cells and the vertebrate endothelium is not clear.

In contrast, vertebrate vessels are completely lined by endothelium, from cyclostomes to mammals. The presence or absence of the endothelium in the animal kingdom is schematically shown in the left part of Fig. 1.

\section{2) Vascular muscle}

The vascular muscles of invertebrates are diverse $(10$,

Components in vascular wall

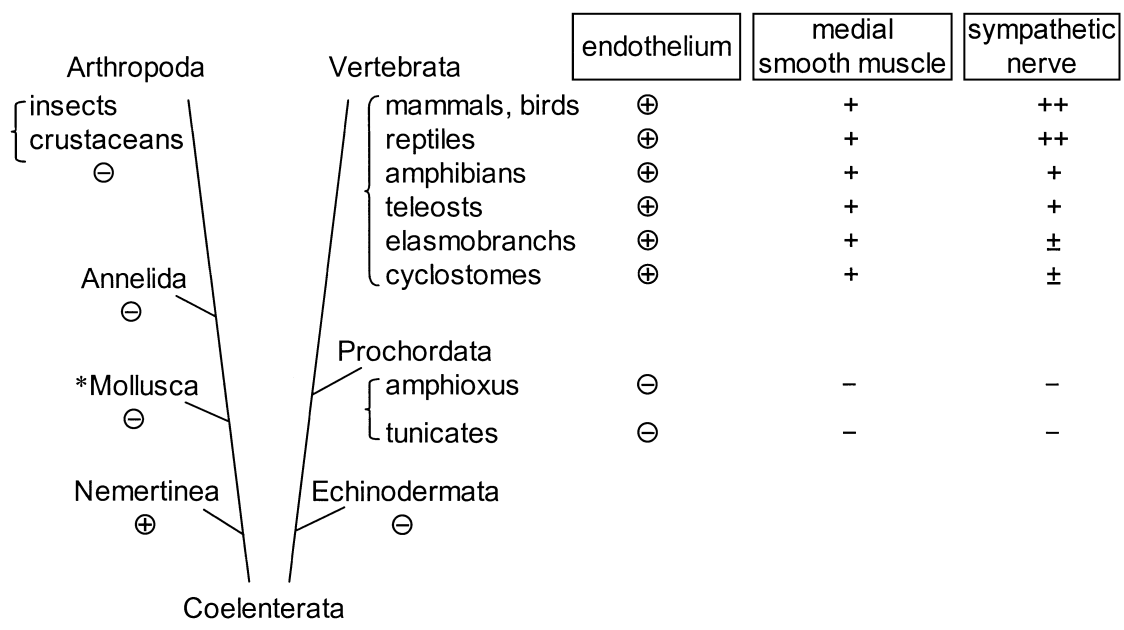

Fig. 1. Scheme showing presence or absence of endothelium $(\oplus, \ominus)$, medial smooth muscle $(+,-)$ and sympathetic nerves $(++\sim-)$ in the vascular wall throughout the animal kingdom. In grading the density of sympathetic innervation, development of the whole sympathetic nervous system is taken into consideration. Phylogenetically, all three components seem to have appeared and developed in the vertebrate circulatory system. *Endothelium-like cells exist in some parts of vessels in octopus or squid. 
12, 24, 25). Certain aspects of information will be presented here.

Structure of the blood vessel wall without endothelium and the nature of contractile vessels will be first described, according to a few papers of electron microscopic studies on the circulatory system of Nereis japonica (clamworm, an annelid) (8), the tunicate heart (13) and a comparative study of amphioxus, tunicate and the newt embryo $(19,20)$.

\section{Structure of the wall of endotheliumless vessels}

The vascular lumen of these three species of invertebrates (Nereis, tunicate and amphioxus) is essentially composed of tissue spaces or tubular systems which are connected with tissue spaces (morphologically, it is an open circulatory system in the sense that there is no endothelial lining which separates blood plasma from tissue fluid). The vessels are tubes which simply penetrate gelatinous tissue, blood sinuses located in the intestinal wall, vessels running along the digestive tube ventromedially or vessels running freely through the coelom.

In the Nereis, regardless of location, the basic structure of the wall of all blood vessels is similar, being composed of a basal lamina of neighboring tissue and a fibrous connective tissue layer made up of collagen fibrils. On the luminal side, this layer is in direct contact with blood. The layer is regionally variable in thickness. In some portions, it is extremely attenuated or even absent, where the basal lamina is exposed to the lumen and comes into direct contact with blood. The outer surface of the basal lamina is covered, depending on location, by peritoneal cells, gut epithelium or epidermis. In the dorsal longitudinal vessel, the peritoneal cells differentiate into myoepithelium and the vessel is contractile. The blood vessels of Nereis have no true endothelium, but scattered amoebocytes are found clinging to their inner surfaces. Nakao (8) concluded that the vascular lumen in Nereis is essentially an interstitial space, and the system, which has been known as a typical "closed" circulatory system in annelids, is actually an open circulatory system.

In the tunicate heart, its cavity is separated from the basal lamina of the muscle cell layer by a thin layer of fibrous tissue that is similar in texture to the interstitial tissue in other parts of the animal.

\section{Myoepithelium in pulsatile vessels and its relation with origin of the vertebrate heart}

The pattern of circulatory channels of the three invertebrates is more or less similar to the basic pattern of vertebrate embryonic circulation (Figs. 2 and 3). Blood (or hemolymph) is propelled by the pulsatile portion of vessels which develop in some region of the channels, for example, the heart in tunicate, the pulsatile vessel running subintestinally in amphioxus, or the pulsatile dorsal longitudinal vessel in Nereis. The basic structure of the wall is homologous among these heart and vessels - a single layer of visceral coelomic epithelium which becomes a trough or tubular shape (Fig. 2B). The epithelium of the pulsatile regions is composed of contractile myoepithelial cells containing myofilaments.

Hirakow $(19,20)$ further clarified that, apart from the existence of the endothelium, the same is true in the development of the early tubular heart of the newt embryo. Thus the origin of vertebrate cardiac muscle is also nothing but a single layer of the coelomic visceral epithelium (Fig. 2A). He pointed out the possibly significant role of coelomic epithelium in driving the body fluid of the Metazoa, including the chordates, as well as some invertebrates such as the annelid, suggesting some phylogenetic relationship with the origin of the vertebrate heart.

In the newt embryo of the stage shown in Fig. 2A and the adult amphioxus (2B), the myoepithelial heart is the sole muscular element of their whole circulatory systems. In the newt vascular wall, medial smooth muscle will appear later (see "Ontogenesis" section).

The myoepithelial cells of the tunicate heart and of the newt embryonic heart contain striated myofibrils $(13,20$, 26). Those in the pulsatile vessel of the earthworm are obliquely striated (27). The cells of the pulsatile vessel of Nereis exhibit similar fine structure (8).

\section{Some other invertebrates}

Crustacean arterial walls generally lack muscle. Instead, cardioarterial valves which are muscular and innervated are reported in crabs (28), lobsters $(28-30)$ and crayfish (30), as well as in Bathynomus doederleini, an isopod crustacean (31). An exceptional presence of striated musculature was reported in the wall of the dorsal aorta of the palinurid lobster, which may be a remnant of the abdominal heart (32).

Among mollusks, it was reported that the wall of octopus aorta consists of a layer of endothelium-like cells, a thick basement membrane, and internal circular and outer longitudinal muscle layers (both smooth muscle). The "endothelial" cells, however, are not attached to each other by any form of specialized junctions. In smaller arteries, the lining of "endothelium" is less complete, and the pericytes contain myofilaments $(22,23)$. In aplysia, arteries that supply the viscera contain primarily circular muscle, while those that perfuse somatic tissues generally possess both circular and longitudinal muscle (33).

Interestingly, in an electron microscopic study on developing amphioxus, Hirakow and Kajita (21) found that there were no detectable mesenchymal cells in the body of amphioxus larva, "an epithelial animal", differing greatly from the vertebrate embryo of which body consists of massive mesenchymal tissues. 
A

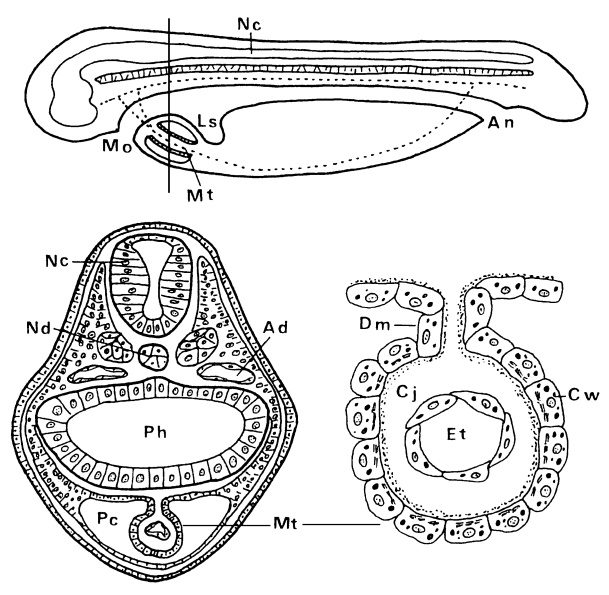

B

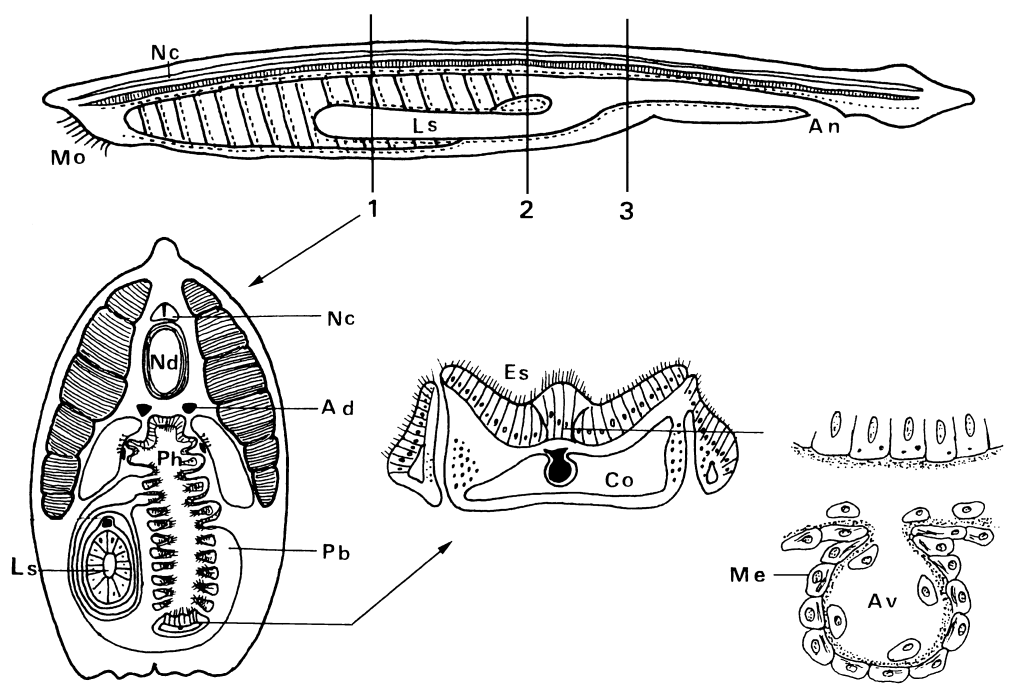

Fig. 2. Comparison of fine structure of the tubular embryonic heart (Mt) of vertebrate (newt) and the subintestinal pulsatile vessel (Av) of prochordate (amphioxus). Their contractile walls ( $\mathrm{Cw}$ and $\mathrm{Me}$ ) are homologous, both being the visceral coelomic myoepithelium. Myofibrils are seen in the basal region of the epithelial cells. Dotted lines represent main circulatory channels. A: Tail bud embryo of newt. Whole embryo, section through cardiac region and fine structure of cardiac wall or primitive myocardium. B: Adult amphioxus. Whole body, section through line 1, subendstyle region and fine structure of subintestinal vessel wall. (In cross sections through lines 2 and 3, the same fine structure of the subintestinal vessel wall was observed.) Ad: dorsal aorta, An: anus, Av: ventral aorta (endostyle artery), $\mathrm{Cj}$ : cardiac jelly, Co: coelom, $\mathrm{Cw}$ : cardiac wall (primitive myocardium), Es: endostyle, Et: endothelial tube, Ls: liver sack, Me: coelomic myoepithelium (mesothelium), Mo: mouth, Mt: tubular heart (mesothelial tube), Nc: neural canal, Nd: notochord, Pb: peribranchial cavity, Pc: pericardial cavity (coelom), $\mathrm{Ph}$ : pharynx. (Reproduced, by permission, from reference 20, with modification.)

\section{The vertebrate vessels}

In vertebrates, structure of the vascular wall is characterized by a complete endothelial lining of the lumen, development of surrounding smooth muscle, as well as formation of three distinct layers: the intima, the media and the adventitia. The muscle is either mesodermal or neural crest origin. From a phylogenetic viewpoint, it is likely that the medial smooth muscle is a tissue that appeared after the emergence of and in association with the endothelial tubular system in vertebrates in the course of evolution.

\section{3) Sympathetic nerves}

In the evolution of the chordates (prochordates and vertebrates), the parasympathetic and sympathetic nervous systems arose separately. The former is phylogenetically older and are distributed to the digestive tube and other viscera to control their functions. The sympathetic nerves appeared later and developed in close relation with the vascular system. It seems that, since the days of Gaskell and Langley, many authors have basically agreed with such a view $(34-41)$. This view has been restated and modified, although with some inconsistencies as well, as quoted in the following.

In his discussion of the phylogenetic origin of the sympa- thetic nervous system, Gaskell (1916) (34) emphasized a close interdependence among the vascular muscular, chromaffin and sympathetic nervous systems. He also pointed out that, in amphioxus, there is no evidence of any of these structures. After comparing the sympathetic systems of the lower vertebrates, Dipnoi, Teleostei, Ganoidei and Cyclostomata, he concluded: "Comparative anatomy thus shows most clearly the close relationship between the chromaffin and sympathetic systems, and the remarkable increase in the latter system, apparently at the expense of the former, which has taken place, commencing in the lowermost group of vertebrates."

In the conclusion of his lecture "Chemical transmission of the effects of nerve impulses" (36), Dale stated "We get an impression of the cholinergic mechanism as having the more general application in the functions of the nervous system, and probably an earlier origin in evolution, and of the adrenergic mechanism as a more specialized and probably a more recent development. I believe that such a conception would have been congenial to the thought of .... the late Professor W.H. Gaskell".

Burnstock (39) summarized the evolution of the autonomic nervous system as follows. The cranial nerves, in which parasympathetic autonomic components are found, 


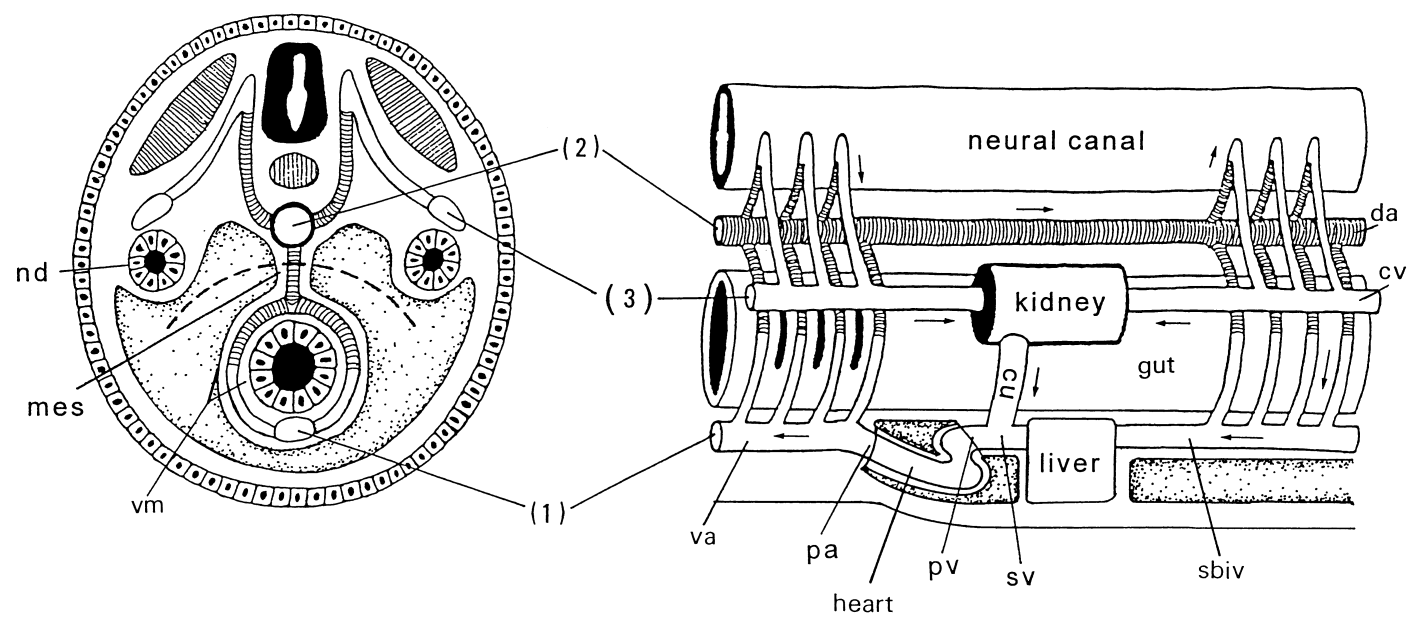

Fig. 3. The basic pattern of vertebrate embryonic circulatory system. Left: cross section, Right: lateral view. (1): subintestinal system, (2): supraintestinal system, (3): renal system. Arrows indicate the direction of blood flow. The subintestinal and supraintestinal systems are connected by the branchial and the mesenteric vessels, and thus circulation of the digestive tube (gut) is first established. The cardinal veins (the renal system) then appear along the nephric ducts, as renal portal veins. Intersegmental arteries perfuse the body wall (neural canal, in the figure); the venous blood flows into the cardinal veins and returns to the sinus venosus via the ducts of Cuvier. It should be noted that the basic pattern of circulation is formed of the heart and the endothelial tubes. cu: ductus Cuvieri, cv: cardinal vein, da: dorsal aorta, mes: mesentery, nd: nephric duct, pa: porta arteriosa, pv: porta venosa, sbiv: subintestinal vein, sv: sinus venosus, va: ventral aorta, vm: visceral mesoderm. (Reproduced from reference 47 , with modification.)

are identified in all vertebrates. The spinal sympathetic outflow is not arranged in segmental ganglia in cyclostome fish. In elasmobranch fish, there is a series of paravertebral ganglia, but they are not in the form of a compact sympathetic chain. A well-defined sympathetic chain first appears in teleost fish and is retained throughout higher vertebrates.

Although the lamprey has no organized sympathetic system, large-cored-vesicle-containing neurons, nerve fibers and endings were found in various peripheral tissues including blood vessel walls. Some of these structures were shown to be monoaminergic or assumed to be vasomotor $(42,43)$.

In Botár's view $(37,38)$, three main constituent parts can be distinguished in the vegetative nervous system: the enteric nerve-cell system in the wall of the digestive tube, the vascular nerve cell system along the wall of the main vascular trunk, and the visceral part of the nervous system of the organism which innervate the vegetative apparatuses and systems. The enteric nerve cell system is the oldest, phylogenetically. It appears in Coelenterata and is today present in all animals. The vascular nerve-cell system, which is the youngest part of the vegetative nervous system, appears in Cyclostomata and occurs exclusively in Vertebrata. These nerve cells form prevertebral sympathetic and paravertebral sympathetic ganglia. The prevertebral ganglia lie close to the origin of the visceral blood vessels from the aorta. The paravertebral ganglia are positioned segmentally at the origin of the parietal blood vessels. The nerve fibers that originate from the vascular nerve-cell system primarily innervate the vessels, but along these, they reach all parts of the body and secondarily innervate other organs and tissues. When the effector organs have earlier innervation from other main components of the vegetative nervous system, these organs become bi-innervated.

The comparative anatomy and evolution of the autonomic nervous system was recently reviewed by Gibbins (40). In his discussion of the general features and evolution of the spinal autonomic outflow in vertebrates, he stressed an evolutionary trend of a shift from chromaffin cells to sympathetic neurons as the main source of regulation of the cardiovascular system. Developmental studies provide good evidence, both biochemically and morphologically, that the shift is a realistic scenario. Both classes of cells are of neural crest origin.

Morris and Nilsson (41) pointed out that although the density of innervation of vasculature by catecholamine synthesizing neurons is, in general, lower in amphibians than other tetrapods, there is no systematic difference between the densities of innervation in reptiles compared with mammals. This can be related to their need to deal with gravitational effects on the circulation.

Gibbins began his review (40) by asking whether or not Langley's scheme for classifying the various components of the autonomic nervous system, the concept of three main divisions, the sympathetic, the parasympathetic and the enteric divisions, could be applied across the vertebrate classes. In conclusion, he stated "The evidence, such as it 
is, seems to say that indeed it can. The enteric neurons comprise a separate autonomic division in all classes of vertebrates. It is almost certainly the most primitive component of the autonomic system, apparently being present in non-vertebrate chordates, such as amphioxus, that lack any other obvious components of an "autonomic" nervous system."

Another point is to be noted. In his earlier work, Botár (44) divided the postganglionic sympathetic system into two ganglion chains, the visceral (prevertebral) and parietal (paravertebral). On the basis of comparative anatomical studies, he identified the cervical sympathetic trunk as the "visceral" part of the sympathetic system. It included the superior and the middle cervical ganglia and ventral half of the stellate ganglion. The stellate ganglion was bipartite, its dorsal half being the first "parietal" ganglion. This is notable, since the cervical and stellate ganglia are often regarded as parts of the paravertebral sympathetic trunk.

\section{4) Summary of phylogenesis}

It seems certain that there was an evolutionary discontinuity between the prochordates and the vertebrates in the development of the three components of the vascular wall: the endothelium, medial smooth muscle and sympathetic nerves (Fig. 1). We assume that: i) in the course of evolution, a circulatory system composed of endothelial tubes first formed in vertebrates, ii) medial smooth muscle then appeared for regulation of the system, and iii) innervation of this muscle tissue by sympathetic nerves took place.

\section{Ontogenesis of the vertebrate vascular system}

Ontogenesis of the vertebrate vascular system proceeds in at least three steps: i) appearance of endothelial tubular network surrounding the digestive tube; ii) formation of major channels leading to a basic pattern of embryonic circulation (Figs. 2A and 3); and iii) successive rearrangement of channels, resulting ultimately in the adult form of circulation.

Up to the second stage, the whole vascular system is composed of endothelial tubes. During the third stage, smooth muscle and nerves successively appear in the vascular wall, site to site. Thus, the endothelium is the primary structure of vertebrate blood vessels. Mesenchymal cells accumulate around the major channels and differentiate into smooth muscles $(9,11,26,45,46)$. The latter then receive sympathetic innervation. It can be said that the sequential appearance of endothelium, medial smooth muscle and sympathetic nerves assumed for their phylogenesis is just realized in the course of ontogenetic development. Figure 3 shows the basic pattern of the embryonic circulatory system that commonly appears in vertebrates $(47,48)$.

\section{The hypothesis and some implications}

Based on the above, we propose that "the sympathetic nerve/medial smooth muscle system" may be regarded as a vascular neuroeffector mechanism that appeared and developed anew in the vertebrate circulation for systemic regulation of the "endothelium-lined closed vascular system".

Our view of the "sympathetic nerve/medial smooth muscle system" may explain some of the differences between sympathetic and parasympathetic vascular innervation found in vertebrates. The parasympathetic nerves are thought to have been distributed to the digestive tube and other viscera. We assume, from a phylogenetical viewpoint, that vertebrate vascular smooth muscle, which developed after the emergence of and in association with the endothelial tubular system, was not, originally, the target tissue of the parasympathetic nerves as a whole. This may account for the fact that the sympathetic nerves distribute widely to the whole vascular system, while the parasympathetic nerves distribute only to limited sites in the vertebrate vascular system.

This view is consistent with our earlier observations of the dog venous system, which show that cholinergic excitatory innervation was localized in a group of veins: the portal, mesenteric and hepatic veins and the middle segment of the inferior vena cava $(3,4,49,50)$. The innervation was detected, both in vitro and in vivo, as a cholinergic component in neurally evoked contractile responses, which was augmented by anticholinesterase treatment and blocked by atropine. These veins are rich in longitudinal muscle, in addition to the circular muscle, and exhibit a spontaneous rhythmic activity, like intestinal muscle. These veins are closely related to the digestive tube in their embryogenesis, and their smooth muscle probably derives from a common origin with visceral musculature, namely, from the visceral mesoderm, either the coelomic epithelium or mesenchymal cells. It is therefore probable that the cholinergic nerves which innervate the viscera also distribute to these veins. Whereas the development and transformation of circulatory channels have been studied in good detail, information is still wanted about the sequence of appearance and the direct origin of the medial smooth muscle at key sites of the vascular system.

Finally, we would like to mention a recent report on dynamics of endothelium-muscle cell contacts in the coronary artery of the dog along its ontogenesis (51). Close contacts were observed between protrusions of endothelial and smooth muscle cells, through perforated internal elastic lamina. At the site of contact, the basal membrane disappeared, and formation of gap-junctions was probable. The frequency of the myo-endothelial contacts was highest in fetuses and decreased with age. We suppose that the 
finding may suggest an aspect of the endothelium-associated development of medial smooth muscle in vertebrate vascular wall.

\section{Acknowledgments}

The authors are deeply grateful to the late Prof. Ryoji Ura, Tohoku University School of Medicine, the late Prof. Shigeo Miki, the Tokyo National University of Fine Arts and Music, the late Prof. Reiji Hirakow, Saitama Medical School, three distinguished anatomists, for their kind, instructive advice and help over many years.

\section{REFERENCES}

1 Tsuru H, Ishikawa $\mathrm{N}$ and Shigei T: Responsiveness of isolated dog veins to bradykinin and other bioactive peptides: distribution of sensitivity to bradykinin and possible correlation with genesis of the venous system. Blood Vessels 13, 238-248 (1976)

2 Ishikawa N, Ichikawa T and Shigei T: Possible embryogenetical differences of the dog venous system in sensitivity to vasoactive substances. Jpn J Pharmacol 30, 807 - 818 (1980)

3 Nakazato Y, Ohga A, Shigei T and Uematsu T: Extrinsic innervation of the canine abdominal vena cava and the origin of cholinergic vasoconstrictor nerves. J Physiol (Lond) 328, 191 203 (1982)

4 Shigei $\mathrm{T}$, Ichikawa $\mathrm{T}$, Ishikawa $\mathrm{N}$, Uematsu $\mathrm{T}$ and Tsuru $\mathrm{H}$ : Functional venous characteristics in relation to embryology. In Vascular Neuroeffector Mechanisms: 4th International Symposium, Edited by Bevan JA, Fujiwara M, Maxwell RA, Mohri K, Shibata S and Toda N, pp 203-208, Raven Press, New York (1983)

5 Yoshioka K, Furuta T, Hayakawa A, Ishikawa N and Shigei T: Excitatory cholinergic innervation in canine portal and mesenteric veins. Am J Physiol 255, H288 - H294 (1988)

6 Shigei T, Tsuru H, Ishikawa N and Yoshioka K: Significance of endothelium and sympathetic nerve/medial smooth muscle in the vertebrate vascular system: an embryological view. Pharmacol Toxicol 83, Suppl 1, 99 (abstract) (1998)

7 Leydig F: Lehrbuch der Histologie des Menschen und der Tiere. Sohn \& Comp., Frankfurt a.M. (1857) (adopted from Nakao T (8))

8 Nakao T: An electron microscopic study of the circulatory system in Nereis japonica. J Morphol 144, 217 - 236 (1974)

9 Altschul R: Endothelium - Its Development, Morphology, Function and Pathology. McMillan Co, New York (1954)

10 Martin AW and Johansen K: Adaptation of the circulation in invertebrate animals. In Handbook of Physiology, Section 2, Vol 3, Edited by Hamilton WF and Dow P, pp 2545-2581, Am Physiol Soc, Washington DC (1965)

11 Mori T: The phylogeny of blood vessels. Tokyo Tanabe Q 30, 11 - 20 (1979) (in Japanese)

12 Mori T and Shida H: Development of blood vessels. In Atherosclerosis, Vol 1, Edited by Oshima K, Shimamoto T and Goto Y, pp 1 - 12, Asakura, Tokyo (1979) (in Japanese)

13 Ichikawa A: The fine structure of the tunicate heart. In Electron Microscopy, Vol 2, Edited by Uyeda R, pp 695 - 696, Maruzen Co, Tokyo (1966)

14 Baccetti B and Bigliardi E: Studies on the fine structure of the dorsal vessel of arthropods. I. The "heart" of an orthopteran. Z Zellforsch 99, 13 - 24 (1969)
15 Nakao T: Electron microscopic study of the open circulatory system of the shrimp, Caridina japonica. I. Gill capillaries. J Morphol 144, 361 - 380 (1974)

16 Nakao T: The fine structure and innervation of gill lamellae in Anodonta. Cell Tiss Res 157, 239 - 254 (1975)

17 Jensen H: Ultrastructure of the dorsal hemal vessel in the sea-cucumber Parastichopus tremulus (Echinodermata: Holothuroidea). Cell Tiss Res 160, 355 - 369 (1975)

18 Moller PC and Philpott CW: The circulatory system of Amphioxus (Branchiostoma floridae). 1. Morphology of the major vessels of the pharyngeal area. J Morphol 139, 389 - 406 (1973)

19 Hirakow R: The vertebrate heart in phylogenetic relation to the prochordates. In Vertebrate Morphology, Edited by Duncker HR and Fleischer G, pp 367-369, Gustav Fischer Verlag, Stuttgart/New York (1985)

20 Hirakow R: Developmental anatomy of the heart. J Saitama Med Sch 12, 85 - 95 (1985) (in Japanese)

21 Hirakow R and Kajita N: Electron microscopic study of the development of amphioxus, Branchiostoma belcheri tsingtauense: The nurula and larva. Acta Anat Nippon 69, 1-13 (1994)

22 Barber VC and Graziadei P: The fine structure of cephalopod blood vessels. I. Some smaller peripheral vessels. Z Zellforsch 66, 765 - 781 (1965)

23 Barber VC and Graziadei P: The fine structure of cephalopod blood vessels. III. Vessel innervation. Z Zellforsch 77, $162-174$ (1967)

24 Prosser CL (Ed.): Comparative Animal Physiology, Saunders, Philadelphia (1973)

25 Prosser CL: Evolution and diversity of nonstriated muscles. In Handbook of Physiology, Section 2, Vol 2, Edited by Bohr DF, Somlyo AP, Sparks Jr HV and Geiger SR, pp 635-670, Am Physiol Soc, Bethesda (1980)

26 Hirakow R: Origin and differentiation of the chordate heart. In Trends in Vertebrate Morphology, Edited by Splechtna $\mathrm{H}$ and Hilgers H, pp $261-263$, Gustav Fischer Verlag, Stuttgart /New York (1989)

27 Uehara Y, Campbel GR and Burnstock G: Muscle and Its Innervation, an Atlas of Fine Structure. Edward Arnold, London (1976)

28 MacMahon BR: Factors controlling the distribution of cardiac output in decapod crustaceans. In Phylogenetic Models in Functional Coupling of CNS and the Cardiovascular System, Edited by Hill RB, Kuwasawa K, McMahon BR and Kuramoto T, pp 51 - 61, Karger, Basel (1992)

29 Kuramoto T, Hirose E and Tani M: Neuromuscular transmission and hormonal modulation in the cardioarterial valve of the lobster, Homarus americanus. In Phylogenetic Models in Functional Coupling of CNS and the Cardiovascular System, Edited by Hill RB, Kuwasawa K, McMahon BR and Kuramoto T, pp $62-69$, Karger, Basel (1992)

30 Reiber CL, McMahon BR and Burggren WW: Redistribution of cardiac output in response to hypoxia: a comparison of the freshwater crayfish, Procambarus clarkii, and the lobster, Homarus americanus. In Phylogenetic Models in Functional Coupling of CNS and the Cardiovascular System, Edited by Hill RB, Kuwasawa K, McMahon BR and Kuramoto T, pp $22-28$, Karger, Basel (1992)

31 Fujiwara-Tsukamoto Y, Kuwasawa K and Okada J: Anatomy and physiology of neural regulation of haemolymph flow in the lateral arteries of the isopod crustacean, Bathynomus doeder- 
leini. In Phylogenetic Models in Functional Coupling of CNS and the Cardiovascular System, Edited by Hill RB, Kuwasawa K, McMahon BR and Kuramoto T, pp 70-85, Karger, Basel (1992)

32 Burnett BR: Striated muscle in the wall of the dorsal abdominal aorta of the California spiny lobster, Panulirus interruptus. J Crustacean Biol 4, 560 - 566 (1984)

33 Koester J and Koch UT: Neural control of the circulatory system of Aplysia. Experientia 43, 972 - 980 (1987)

34 Gaskell WH: The Involuntary Nervous System. Chapter 11, Longmans, Green \& Co, London (1916)

35 Langley JN: The Autonomic Nervous System. Part I. Heffer, Cambridge (1921)

36 Dale HH: Chemical transmission of the effects of nerve impulses. Br Med J I, 835 - 841 (1934) (reproduced in Dale HH: Adventures in Physiology, pp 530-545, The Welcome Trust, London (1965))

37 Botár J: Phylogenetische Evolution des vegetativen Nervensystems. Anat Anz 118, 488 - 494 (1966)

38 Botár J: Phylogenetic evolution of the vegetative nervous system. Acta Neurovegetativa 30, 342 - 349 (1967)

39 Burnstock G: Evolution of the autonomic innervation of visceral and cardiovascular system in vertebrates. Pharmacol Rev 21, $247-324$ (1969)

40 Gibbins I: Comparative anatomy and evolution of the autonomic nervous system. In Comparative Physiology and Evolution of the Autonomic Nervous System, Edited by Nilsson S and Holmgren S, pp 1-67, Harwood Academic Publishers, Chur (1994)

41 Morris JL and Nilsson S: The circulatory system. In Comparative Physiology and Evolution of the Autonomic Nervous System, Edited by Nilsson S and Holmgren S, pp $193-246$,
Harwood Academic Publishers, Chur (1994)

42 Nakao T and Ishizawa A: An electron microscopic study of autonomic nerve cells in the cloacal region of the lamprey, Lampetra japonica. J Neurocytol 11, 517 - 532 (1982)

43 Homma S: Physiology and pharmacology of putative transmitters in lamprey central nervous system. Prog Neurobiol 20, $287-311$ (1983)

44 Botár J: Nouvelle orientation dans la systématisation du sympathique. C R Assoc Anat 28, 85 - 101 (1933)

45 Hirakow R and Hiruma T: Scanning electron microscopic study on the development of primitive blood vessels in chick embryos at the early somite stage. Anat Embryol 163, 299 - 306 (1981)

46 Nakamura H: Electron microscopic study of the prenatal development of the thoracic aorta in the rat. Am J Anat 181, 406-418 (1988)

47 Miki S: Genesis of the splenic vein. In Vascular Neuroeffector Mechanisms: 4th International Symposium, Edited by Bevan JA, Fujiwara M, Maxwell RA, Mohri K, Shibata S and Toda N, pp 195 - 201, Raven Press, New York (1983)

48 Shigei T, Ishikawa N and Hirakow R: An embryological aspect of cholinergic innervation in the cardiovascular system. Jpn J Pharmacol 58, Suppl II, 302P (1992)

49 Ichikawa $\mathrm{T}$, Ishikawa $\mathrm{N}$ and Shigei $\mathrm{T}$ : Innervation of the canine inferior vena cava: Distribution of adrenergic and cholinergic excitatory fibers among the embryologically distinct segments. Blood Vessels 16, 155 - 162 (1979)

50 Yoshioka K: Hepatic veins belong to "the veins of the digestive tube" in the dog. Jpn J Pharmacol 46, $424-427$ (1988)

51 Kristek F and Gerová M: Dynamics of endothelium-muscle cell contacts in the coronary artery of the dog in ontogeny. Acta Anat 158, 166 - 171 (1997) 